\title{
Arsenic Accumulation in Duckweed (Spirodela polyrhiza L.): A Good Option for Phytoremediation
}

\author{
M. Azizur Rahman ${ }^{*}$ 1; Hiroshi Hasegawa ${ }^{*}$ 1; Kazumasa Ueda'; Teruya Maki ${ }^{1}$; Chikako \\ Okumura1; $^{1}$ M. Mahfuzur Rahman²
}

${ }^{1}$ Graduate School of Natural Science \& Technology, Kanazawa University, Kakuma, Kanazawa 920-1192, Japan; ${ }^{2}$ Department of Botany, Faculty of Biological Sciences, Jahangirnagar University, Savar, Dhaka-1342, Bangladesh.

\author{
*Corresponding author \\ E-mail: arahman@stu.kanazawa-u.ac.jp \\ hhiroshi@t.kanazawa-u.ac.jp
}

Tel/Fax: 81-76-234-4792

\begin{abstract}
Some unavoidable drawbacks of traditional technologies have made phytoremediation a promising alternative for removal of arsenic from contaminated soil and water. In the present study, the potential of an aquatic macrophyte Spirodela polyrhiza L. for phytofiltration of arsenic, and the mechanism of the arsenic uptake were investigated. The S. polyrhiza L. were grown in three test concentrations of arsenate and dimethylarsinic acid (DMAA) (i.e. 1.0, 2.0
\end{abstract}


and $4.0 \mu \mathrm{M}$ ) with 0 (control), 100 or $500 \mu \mathrm{M}$ of phosphate. One control treatment was also set

for each test concentrations of arsenic. The $\mathrm{PO}_{4}{ }^{3-}$ concentration in control treatment was 0.02 $\mu \mathrm{M}$. When S. polyrhiza L. was cultivated hydroponically for $6 \mathrm{~d}$ in culture solution containing $0.02 \mu \mathrm{M}$ phosphate and $4.0 \mu \mathrm{M}$ arsenate or DMAA, the arsenic uptake was $0.353 \pm 0.003 \mu \mathrm{mol}$ $\mathrm{g}^{-1}$ and $7.65 \pm 0.27 \mathrm{nmol} \mathrm{g}^{-1}$, respectively. Arsenic uptake into S. polyrhiza L. was negatively ( $p$ $<0.05)$ correlated with phosphate uptake when arsenate was applied to the culture solutions owing to similar in the sorption mechanism between $\mathrm{AsO}_{4}{ }^{3-}$ and $\mathrm{PO}_{4}{ }^{3-}$, and positively $(p<$ 0.05) correlated with iron uptake due to adsorption of $\mathrm{AsO}_{4}{ }^{3-}$ onto iron oxides. Thus, the $S$. polyrhiza L. accumulates arsenic by physico-chemical adsorption and via the phosphate uptake pathway when arsenate was added to the solutions. These results indicate that S. polyrhiza L. would be a good arsenic phytofiltrator. In contrast, DMAA accumulation into S. polyrhiza L. was neither affected by the phosphate concentration in the culture nor correlated $(p>0.05)$ with iron accumulation in plant tissues, which indicates that S. polyrhiza L. uses different mechanisms for DMAA uptake.

Keywords: Arsenate, DMAA, Duckweed (Spirodela polyrhiza L.), Mechanism, Uptake, Physico-chemical adsorption.

\section{Introduction}

Arsenic has recently drawn attention due to its chronic and epidemic toxic effects to humans through widespread contamination of water and food crops through natural release of the element from aquifer rocks in Bangladesh (Fazal et al., 2000; Smith et al., 2000; Hopenhayn, 2006) and West Bengal, India (Chowdhury et al., 2000). Geogenic arsenic contamination in aquifer rocks has also been reported in Thailand (Visoottiviseth et al., 2002), Vietnam, Inner Mongolia, Greece, Hungary, U.S.A., Ghana, Chile, Argentina and Mexico (O’Neill, 1995; Smedley and Kinniburgh, 2002).

Some unavoidable limitations of the traditional chemical and physical methods have made phytoremediation, a plant-based green technology, a viable alternative to remediate environmental pollution (Cunningham and Berti, 1993; Raskin et al., 1994b; Raskin et al., 
1994a; Salt et al., 1998). Its relative inexpensiveness and eco-friendliness have made it an attractive method for water and soil remediation (Raskin et al., 1994a). Microorganisms have the potential to degrade environmental pollutants (Ahmann et al., 1997), while some plants have the ability to accumulate toxic metals at high concentrations (McGrath et al., 1998). Arsenic, accumulated into plants primarily through their root system, is not readily translocated to the shoots (Raskin et al., 1994a; Komar et al., 1995). Brooks et al. (1977) first used the term "hyperaccumulators" to describe those plants that uptake and accumulate metals more than $1000 \mu \mathrm{g}$ metal $\mathrm{g}^{-1}$ dry mass (Visoottiviseth et al., 2002) which is still in common use (Reeves and Baker, 2000). Agrostis castellana; Agrostis delicatula (De Koe, 1994), Bidens cynapiifolia (Bech et al., 1997), Chinese brake fern (Pteris vittata L.) (Ma et al., 2001) and silver fern (Pityrogramma calomelanos L.) (Gulz et al., 2005) have been reported to be arsenic hyperaccumulators. In particular, Chinese brake ferns remove a formidable quantity of arsenic from soil (Komar et al., 1998; Gulz et al., 2005), and store it in the fronds (Tu et al., 2002; Gulz et al., 2005).

Besides contamination of the soil, contamination of water by geogenic arsenic has caused severe direct or indirect human health effects. Effective remediation of such water is currently an urgent necessity. Aquatic macrophytes can be a good remediation option, because a few species have already been reported to accumulate arsenic from water (Robinson et al., 2003; Mkandawire and Dudel, 2005). Arsenate is the predominant species in the oxic water and arsenate and arsenite are bioavailable forms to the plants in the aquatic systems (Sizova et al., 2002). The dynamics of arsenate exchange between water and adsorbing colloids are analogous to those of phosphate, though the competition for exchange sites favors phosphate over arsenate (Mkandawire et al., 2004).

The Lemna gibba L. and the Lemna minor L. are the most studied species of Lemnaceae family in phytoremediation and ecotoxicology (Mkandawire et al., 2004; Mkandawire and Dudel, 2005). Great duckweed (S. polyrhiza L.) belonging to the member of Lemnaceae family under the group monocotyledons was selected for the present study because of its fast growth, wide distribution, short life span and stability to environmental changes (Landolt and Kandeler, 1987; Lemon et al., 2001; Khondker, 2003). Moreover, the great duckweed (Spirodela polyrhiza L.) may surpass the know results of lesser duckweed (Lemna spp.) and 
thus, we looked for a less known area. Inorganic arsenic species have been studied extensively in terms of uptake and accumulation by aquatic macrophytes (Robinson et al., 2003; Mkandawire and Dudel, 2005). Little is done using other arsenic species. Moreover, arsenate and DMAA are the major species in the oxic aquatic system. Hence, the accumulation and mechanisms of arsenate (inorganic species) and DMAA (organic species) by S. polyrhiza L. were investigated in the present study.

\section{Materials and Methods}

\section{Plant Cultivation}

The S. polyrhiza L., collected from a rice field in Manikgonj of Dhaka, Bangladesh, was stockcultured in a green house for 2 wk using standard Murashige and Skoog (MS) culture solution (Table 1). The experiment was conducted for $6 \mathrm{~d}$ with the conditions being set as 14:10 $\mathrm{h}$ light/dark schedule, $100-125 \mu \mathrm{E} \mathrm{m}^{-2} \mathrm{~s}^{-1}$ light intensity, $75 \%$ humidity, $22{ }^{\circ} \mathrm{C}$ and $20{ }^{\circ} \mathrm{C}\left( \pm 2{ }^{\circ} \mathrm{C}\right)$ temperatures for day and night, respectively. The $S$. polyrhiza L. were exposed to three test concentrations (i.e. 1.0, 2.0 and $4.0 \mu \mathrm{M}$ ) of arsenate and DMAA with 0.02 (control), 100 or $500 \mu \mathrm{M}$ of phosphate. One control treatment was also set for each test concentrations of arsenic.

\section{Inoculation Procedure}

Before incubation, the $S$. polyrhiza L. plants from the stock-culture were rinsed three times superficially with deionized (DI) water to remove particles attached to the plant surfaces. An amount of $100 \mathrm{~mL}$ culture solution was prepared in each of the 200-mL polystylene test vessels (118 x 86 x $60 \mathrm{~mm})$ and about 120 individual plants were incubated in each of the test vessels. Three were three replicates for each treatment and the experiment was arranged following randomized design (RD) with a total of 36 vessels. Stock solutions of arsenate and DMAA were made from $\mathrm{Na}_{2} \mathrm{HAsO}_{4} \cdot 7 \mathrm{H}_{2} \mathrm{O}$ and $\left(\mathrm{CH}_{3}\right)_{2} \mathrm{AsO}_{2} \mathrm{Na} \cdot 3 \mathrm{H}_{2} \mathrm{O}$, respectively. Arsenic stock solutions were added to the cultures before inoculation. The plants were grown for $6 \mathrm{~d}$. Changes in the volume of cultures from evaporation and accumulation were compensated by adding DI water in every $2 \mathrm{~d}$ throughout the experiment.

\section{Sample Preparation and Chemical Analysis}


All plants (about 120 individuals) were harvested after $6 \mathrm{~d}$ of incubation. After rinsing with DI water for four times, plants were kept on clean absorbent paper to remove the water from plant surfaces. Then the samples were taken into small ceramic cups and covered with ceramic cover and placed into a drying oven. The samples were dried for $48 \mathrm{~h}$ at $65{ }^{\circ} \mathrm{C}$ until they reached a constant weight. Dried samples were weighted and 0.10-0.20 g samples were taken into 50-mL polyethylene tubes (DigiTubes, SCP Science, Canada). Five $\mathrm{mL}$ of $65 \% \mathrm{HNO}_{3}$ were added and the samples were kept under fume hood for $12 \mathrm{~h}$. The samples were then heated on a heating block (DigiPREP, SCP Science, Canada) at $95{ }^{\circ} \mathrm{C}$ for $2 \mathrm{~h}$. After cooling to room temperature, $3 \mathrm{~mL}$ of $30 \%$ hydrogen peroxide were added to the digests and the samples were heated again at $105^{\circ} \mathrm{C}$ for $20 \mathrm{~min}$ and then diluted to $10 \mathrm{~mL}$ using DI water and stored in 15mL polythene bottles (HDPE, NALGENE ${ }^{\circledR}$, Nalge Nunc International, Rochester, NY). Williams et al. (2005) also digested rice samples at $120^{\circ} \mathrm{C}$ and evaporated to dryness at $160{ }^{\circ} \mathrm{C}$ for arsenic speciation analysis.

The concentrations of arsenic and iron were analyzed by graphite-furnace atomic absorption spectrometer (GF-AAS, Z-8100, Hitachi, Japan). For the determination of arsenic, $5 \mu \mathrm{L}$ of $0.05 \mathrm{M}$ nickel nitrate was added to a $10-\mu \mathrm{L}$ sample as matrix solution in the cuvette. The accuracy of the analysis was checked by the analysis of certified standard reference material 1573a tomato leaf (NIST, USA). The arsenic concentration in certified tomato leaf was $0.112 \pm 0.004 \mu \mathrm{g} \mathrm{g}^{-1}$ dry weight while the measured arsenic concentration was $0.123 \pm 0.009 \mu \mathrm{g}$ $\mathrm{g}^{-1}$. The concentrations detected in all samples were above the instrumental limits of detection $(\geq 0.01 \mu \mathrm{M}$ samples in water). Total phosphate and nitrate were determined spectrophotometrically (APHA, 1998).

Chemicals used in this experiment were of analytical grade. All glassware used was washed with detergent solution, $3 \mathrm{M} \mathrm{HCl}$ and finally with DI water for eight times before use. In each analytical batch, at least two reagent blanks and three replicate samples were included.

\section{Data Analysis}

Bioaccumulation values $(\varphi)$ for arsenic in $S$. polyrhiza were defined as $\varphi=g_{u} / g_{L}$, where $g_{u}$ is the mass of arsenic in plant material and $g_{L}$ is the dry biomass (Mkandawire et al., 2004). The experimental data were statistically analyzed for mean separation of treatments according to 
the least significant difference (LSD) at 5\% level by IRRI-STAT 4.0 for windows (developed by the biometrics unit, IRRI, Philippines) and the Pearson correlation coefficient (r) was calculated by SPSS ${ }^{\circledR}$ statistical package (version 10.0 for windows).

\section{Results and Discussion}

\section{Arsenic Accumulation in S. polyrhiza L.}

On exposure to $4.0 \mu \mathrm{M}$ arsenate and $0.02 \mu \mathrm{M} \mathrm{PO}_{4}{ }^{3-}$ (control), S. polyrhiza accumulated $0.353 \pm 0.003 \mu \mathrm{mol} \mathrm{g}{ }^{-1}$ dry weight of arsenic after $6 \mathrm{~d}$ of incubation (Fig. 1a). In contrast, the arsenic accumulation was only $7.65 \pm 0.27 \mathrm{nmol} \mathrm{g}^{-1}$ dry weight when the plants were exposed to DMAA (Fig. 1b). Thus, S. polyrhiza L. accumulated 39 folds more arsenic when exposed to arsenate than those plants exposed to DMAA. The increase of arsenic concentrations in tissues of S. polyrhiza L. showed a strong positive correlation with its concentrations in culture solutions ( $r=0.752$ and 0.801 for arsenate and DMAA, respectively; $p<0.01$ ).

When the concentration of $\mathrm{PO}_{4}{ }^{3-}$ in the culture solution was increased from 0.02 (control) to $500 \mu \mathrm{M}$ with a constant arsenate concentration $(4.0 \mu \mathrm{M})$, a 3.18 folds decrease in arsenic accumulation in S. polyrhiza L. was observed. In contrast, a very small decrease in the accumulation of arsenic was found with the increase of phosphate concentration when DMAA was applied to the culture solutions. The results imply that the arsenic uptake into S. polyrhiza L. is related to the arsenic species and phosphate concentration in the culture solution. Arsenic uptake is depended on phosphate status when the plants were exposed to arsenate while it is independent of phosphate when exposed to DMAA.

Mkandawire and Dudel (2005) reported 0.02 and $106 \mathrm{mg} \mathrm{kg}^{-1}$ dry weight of arsenic accumulation in fronds of Lemna gibba L. (lesser duckweed) when the $\mathrm{PO}_{4}{ }^{3-}$ concentrations in culture solutions were 40 and $0.014 \mathrm{mg} \mathrm{L}^{-1}$. In another study of L. gibba L., Mkandawire et al. (2004) found 1.39 and 1.45 folds decrease in arsenic accumulations when the plants were exposed to $1000 \mathrm{\mu g} \mathrm{L}^{-1}$ arsenate and arsenite, respectively and the $\mathrm{PO}_{4}{ }^{3-}$ concentration in the culture solution was increased from 0.014 to $40 \mathrm{mg} \mathrm{L}^{-1}$. The magnitude of arsenic accumulation in S. polyrhiza L. in relation to $\mathrm{PO}_{4}{ }^{3-}$ concentration is comparable with that of $L$. 
gibba. Arsenic uptake in S. polyrhiza L. decreased by 3.18 folds when the plants were exposed to $4 \mu \mathrm{M}$ arsenate and the $\mathrm{PO}_{4}{ }^{3-}$ concentration in the culture solution was increased from 0.02 to $500 \mu \mathrm{M}$.

\section{Phosphate Uptake in Relation to Arsenic Species}

Phosphate uptake in S. polyrhiza L. was reduced significantly $(p<0.05)$ by arsenate, while DMAA had no significant effect $(p>0.05)$ on its uptake (Table 2). Pearson correlation analysis revealed a strong negative correlation between the arsenate concentrations in culture solutions and phosphate concentrations in plant tissues $(\mathrm{r}=-0.613 ; p<0.05)$. On the other hand, for DMAA, the correlation was not significant $(\mathrm{r}=-0.203 ; p>0.05)$.

Figure 2 shows the relationship between arsenic and total phosphate content in S. polyrhiza L. exposed to either arsenate (Fig. 2a) or DMAA (Fig. 2b). The strong negative correlation between arsenic and phosphate concentrations in S. polyrhiza L. treated with arsenate indicates that the phosphate uptake in this aquatic macrophyte was inhibited by arsenate. De La Rosa et al. (2006) reported the reduction of phosphate uptake into tumbleweed (Salsola kali) when the plant was treated with arsenate. Other researchers (Wang et al., 2002; Patra et al., 2004) reported the inhibition of arsenate uptake by phosphate, which demonstrates that arsenate is accumulated into plants through the phosphate uptake mechanism, even replacing phosphorus from the biomolecules containing phosphate groups.

Most of the experiments demonstrating the suppression of arsenic uptake by phosphate were conducted with terrestrial plants (Carbonell-Barrachina et al., 1998; Cao et al., 2003; Gulz et al., 2005). However, Mkandawire et al. (2004) reported the preference of L. gibba to accumulate more As(III) than $\mathrm{As}(\mathrm{V})$ and suppression of these two inorganic arsenic species uptake by phosphate. They also demonstrated that the effect of phosphate on arsenic uptake seems to differ depending on the plant species as well as the growth conditions. The present study revealed that not only the plant species and growth conditions but also the arsenic species are related to the effect of phosphate on the arsenic uptake into aquatic macrophytes.

\section{Influence of $\mathrm{PO}_{4}{ }^{3-}$ and Fe on Arsenic Uptake by Duckweed}

The accumulation of arsenic in S. polyrhiza L. from solutions containing arsenate decreased significantly ( $p<0.05$ ) with the increase of the phosphate concentration in the culture solution 
for all three concentrations tested (Fig. 1). $\mathrm{AsO}_{4}{ }^{3-}$ is a sorption analog of $\mathrm{PO}_{4}{ }^{3-}$ and competes with it for uptake carriers in the plasmalemma (Mkandawire et al., 2004); hence, more arsenate is expected to be desorbed in the solution with increasing phosphate (Smith and Read, 1997). The arsenate uptake in Lemna gibba L. occurs through the phosphate uptake pathway (Mkandawire and Dudel, 2005) due to similar chemical behavior of $\mathrm{AsO}_{4}{ }^{3-}$ and phosphate and the present findings suggest the same for S. polyrhiza L.

Physico-chemical adsorption, an alternative mechanism for arsenic accumulation into aquatic plants, has been proposed in the literature (Robinson et al., 2006). In this mechanism, suspended oxides of iron (iron plaque) on the aquatic plant surfaces adsorb and accumulate arsenic. The iron concentration in S. polyrhiza L. was positively correlated with that of arsenic $(\mathrm{r}=0.591 ; p<0.05)$ when the plants were exposed to arsenate and was independent $(\mathrm{r}=$ 0.259; $p>0.05$ ) of arsenic when exposed to DMAA (Table 2). Robinson et al. (2006) also reported a positive correlation between arsenic and iron concentrations in aquatic plants since arsenic is adsorbed on iron oxides biosorbed on the plant surfaces. The actual species of arsenic adsorbed was not clear from their studies. The present study suggests arsenate as the predominant species in such incorporation for S. polyrhiza L. as the correlation between arsenic and iron concentrations in plant tissues was significantly positive (Table 2) when arsenate was added to the solutions than that of DMAA. Blute et al. (2004) reported arsenate to be correlated positively with iron in plaque and negatively with iron absorption into the roots of cattail (Typha latifolia) grown in arsenic-contaminated wetland sediments. According to them, the plaque was predominantly $\mathrm{Fe}(\mathrm{III})$ oxyhydroxide and $80 \%$ of the arsenic in it was arsenate and the ferric ion inhibited its mobility into the roots. Another report (Chen et al., 2005) says the same for rice root.

In the present study of S. polyrhiza L., however, arsenic and iron concentrations accumulated into the plants grown in solution containing arsenate and low concentration of phosphate $(0.02$ $\mu \mathrm{M})$ were highly correlated $(p<0.01)$ while they were not significantly correlated $(p>0.05)$ in phosphate-sufficient solution (Fig. 2). This can be attributed to the adsorption of arsenic on iron plaque of plant surfaces in phosphate-deficient solution, which was blocked by phosphate in phosphate-sufficient solution. Thus, S. polyrhiza L. may accumulate arsenic onto the roots 
by physico-chemical adsorption, and into the roots via the phosphate uptake pathway.

Arsenic uptake in S. polyrhiza L. treated with DMAA differs from those treated with arsenate in terms of mechanism and efficiency. There was no significant correlation between the concentrations of arsenic and phosphate in S. polyrhiza L. when the plants were exposed to DMAA (Fig. 2). Arsenate and DMAA differ significantly in their chemical behavior. The similar chemical properties of $\mathrm{As}(\mathrm{V})$ and $\mathrm{P}(\mathrm{V})$ often explain the poor bioavailability of As(V) to plants because $\mathrm{PO}_{4}{ }^{3-}$ is stronger than arsenate in surface chemistry competition (Meharg and Hartley-Whitaker, 2002; Mkandawire et al., 2003) whereas DMAA does not compete with phosphate because of their dissimilarities in chemical properties. Thus, DMAA is not accumulated into S. polyrhiza L. via the phosphate uptake pathway. Pearson correlation analysis between the arsenic and iron concentrations in the plant treated with DMAA also revealed that DMAA was not accumulated via physico-chemical adsorption (Table 2). Moreover, the arsenic and iron concentrations in the plants treated with DMAA were not significantly correlated ( $p>0.05$ ) with phosphate, which suggests that the accumulation of DMAA was independent of phosphate (Fig. 3). The S. polyrhiza L., thus, appears to use a different mechanism for DMAA uptake.

\section{Potential of S. polyrhiza L. for the Phytoremediation of Arsenic}

The arsenic bioaccumulation in S. polyrhiza L. exposed to arsenate was about $79 \%$ higher than those exposed to DMAA. In the culture solutions having $4.0 \mu \mathrm{M}$ of arsenate or DMAA and $0.02 \mu \mathrm{M}$ of phosphate, the arsenic accumulations were $0.353 \pm 0.003 \mu \mathrm{mol} \mathrm{g}{ }^{-1}$ dry weight and $7.65 \pm 0.27 \mathrm{nmol} \mathrm{g}^{-1}$ dry weight, respectively after $6 \mathrm{~d}$ of incubation.

S. polyrhiza L. grows in rice field and prevents the growth of harmful aquatic weeds. Under natural conditions with sufficient nutrients, this plant forms a mat-like covering on the water surface of ponds, lakes and ditches. In addition, S. polyrhiza L. is characterized by fast growth, wide distribution and stability to the environmental changes. Under ideal conditions, its biomass doubles in $24 \mathrm{~h}$ (Khondker, 2003). Moreover, arsenate is the predominant species in the oxic water and arsenate and arsenite are bioavailable forms to the plants in the aquatic systems (Sizova et al., 2002). The present study showed that S. polyrhiza L. accumulates a good amount of arsenic when exposed to arsenate. Thus, S. polyrhiza L. could be a good 
option for phytoremediation.

\section{Acknowledgements:}

This research was supported partly by Grants-in-Aid for Scientific Research (18510071) from the Japan Society for the Promotion of Science, and the Steel Industry Foundation for the Advancement of Environmental Protection Technology, Japan.

\section{Literature cited:}

Ahmann, D., Krumholz, L.R., Hemond, H.F., Lovely, D.R., Morel, F. M.M., 1997. Microbial mobilization of as from sediments of the Aberjona watershed. Environ. Sci. Technol. 31, 2923-2930.

APHA. 1998. Lenore, S.C., Arnold, E.G., Andrew, D.E. (Eds.), Standard Methods for the Examination of Water and Wastewater, $20^{\text {th }}$ edition.

Bech, J., Poschenrieder, C., Llugany, M., Barcelo, J., Tume, P., Toloias, F.J., 1997. As and heavy metal contamination of soil and vegetation around a copper mine in Northern Peru. Sci. Total. Environ. 203, 83-91.

Blute, N.K., Brabander, D.J., Hemond, H.F., Sutton, S.R., Newville, M.G., Rivers, M.L., 2004. Arsenic sequestration by ferric iron plaque on cattail roots. Environ. Sci. Technol. 38, 6074-6077.

Brooks, R.R., Lee, J., Reeves, R.D., Jaffre, T., 1977. Detection of nickeliferous rocks by analysis of herbarium specimens of indicator plants. Geochem-Explor. Env. A. 7, 4957.

Carbonell-Barrachina, A.A., Aarabi, M.A., DeLaune, R.D., Gambrell, R.P., Patrick, W.H., 1998. The influence of arsenic chemical form and concentration on Spartina patens and Spartina alterniflora growth and tissue arsenic concentration. Plant Soil 198, 33-43.

Cao, X., Ma, L.Q., Shiralipour, A., 2003. Effects of compost and phosphate amendments on arsenic mobility in soils and arsenic uptake by the hyperaccumulator, Pteris vittata L. Environ. Pollut. 126, 157-167.

Chowdhury, U.K., Biswas, B.K., Chowdhury, T.R., Samanta, G., Mandal, B.K., Basu, G.C., Chanda, C.R., Lodh, D., Saha, K.C., Mukherjee, S.K., Roy, S., Kabir, S., Quamruzzaman, Q., Chakraborti, D., 2000. Groundwater arsenic contamination in 
Bangladesh and West Bengal, India. Environ. Health Persp. 108, 393-397.

Chen, Z., Zhu, Y.G., Liu, W.J., Meharg, A.A., 2005. Direct evidence showing the effect of root surface iron plaque on arsenite and arsenate uptake into rice (Oryza sativa) roots. New Phytol. 165, 91-97.

Cunningham, S.D., Betri, W.R., 1993. Remediation of contaminated soils with green plants: An overview. In Vitro Cell Dev. Biol. 29, 207-212.

De Koe, T., 1994. Agrostic castellana and Agrostis delicatula on heavy metal and arsenic enriched sites in NE Portugal. Sci. Total Environ. 145, 103-109.

De La Rosa, G., Parsons, J.G., Martinez, A.M., Peralta-videa, J.R., Gardea-Torresdey, J.L., 2006. Spectroscopic study of the impact of arsenic speciation on arsenic/phosphorus uptake and plant growth in Tumbleweed (Salsola kali). Environ. Sci. Technol. 40, 1991-1996.

Fazal, M.A., Kawachi, T., Ichio, E., 2001. Validity of the latest research findings on causes of groundwater arsenic contamination in Bangladesh. Water Int. 26, 380-389.

Gulz, P.A., Gupta, S.K., Schulin, R., 2005. Arsenic accumulation of common plants from contaminated soils. Plant Soil 272, 337-347.

Hopenhayn, C., 2006. Arsenic in drinking water: Impact on human health. Elements 2, 103107.

Huang, J.W., Poynton, C.Y., Kochian, L.V., Elless, M.P., 2004. Phytoremediation of arsenic from drinking water using arsenic-hyperaccumulating ferns. Environ. Sci. Technol. 38, 3412-3417.

Kumar, P.B.A.N., Dushenkov, V., Motto, H., Raskin, I., 1995. Phytoextration- the use of plants to remove heavy metals from soils. Environ. Sci. Technol. 29, 1232-1238.

Komar, K., Ma, L.Q., Rockwood, D., Syed, A.A., 1998. Identification of arsenic tolerant and hyperaccumulating plants from arsenic contaminated soils in Florida. Agron. Abstr. 343.

Khondker M., 2003. Duckweed. In: Sirajul Islam (Ed.). Banglapedia: National Encyclopedia of Bangladesh. Asiatic Society of Bangladesh. Dhaka, Bangladesh.

Landolt, E., Kandeler, R., (Eds.) 1987. The family Lemnaceae: a monographic study. Phytochemistry, Physiology, Application, Bibliography, Vero“ff. Geobot. Volume 2. 
Inst. ETH Stif.

Lemon, G.D., Posluszny, U., Husband, B.C., 2001. Potential and realized rates of vegetative reproduction in Spirodela polyrhiza, Lemna minor, and Wolffia borealis. Aquat. Bot. 70, 79-87.

Ma, L.Q., Komar, K.M., Tu, C., Zhang, W., Cai, Y., Kennelley, E.D., 2001. A fern that hyperaccumulates arsenic. Nature 409, 579.

McGrath, S.P., Dunham, S.J., Atkin, R.K., 1998. An extracting science. Chem. and Industry.

Meharg, A.M., Hartley-Whitaker, J., 2002. Arsenic uptake and metabolism in arsenic resistant and nonresistant plant species. New Physiol. 154, 29-43.

Mkandawire, M., Dudel, E.G., 2005. Accumulation of arsenic in Lemna gibba L. (duckweed) in tailing water of two abandoned uranium mining sites in Saxony, Germany. Sci. Total Environ. 336, 81-89.

Mkandawire, M., Lyubun, Y.V., Kosterin, P.V., Dudel, E.G., 2004. Toxicity of arsenic species to Lemna gibba L. and the influence of phosphate on arsenic bioavailability. Environ. Toxicol. 19, 26-35.

Mkandawire, M., Taubert, B., Dudel, E.G., 2003. Effects of phosphate and ammonium amendments on arsenic and uranium immobilization by Lemna sp. from tailing waters. Proc. of the $2^{\text {nd }}$ European Bioremediation Conference, June 30- July 4, Chania, Greece. 405-408.

O’Neill, P., 1995. Arsenic, In: Alloway, B. J. (Ed.). Heavy Metals in Soils. pp 105-121.

Patra, M., Bhowmil, N., Bandopadhyay, B., Sharma, A., 2004. Comparison of mercury, lead and arsenic with response to genotoxic effects on plant systems and the development of genetic tolerance. Environ. Exp. Bot. 52, 199-223.

Raskin, I., Kumar, P.B.A.N., Dushenkov, S., Salt, D.E., Ensley, B.D., 1994a. Removal of radionuclides and heavy metals from water and soil by plants. OECD Document on Bioremediation. 345-354.

Raskin, I., Kumar, P.B.A.N., Dushenkov, S., Salt, D.E., 1994b. Bioconcentration of heavy metals by plants. Curr. Opin. Biotechnol. 5, 285-290.

Reeves, R.D., Baker, A.J.M., 2000. Metal accumulating plants. In: Raskin, I., Ensley, B.D., (Eds.), Phytoremediation of Toxic Metals: Using Plant to Clean up the Environment. 
John Wiley, New York.

Robinson, B., Duwig, C., Bolan, N., Kannathasan, M., Saravanan, A., 2003. Uptake of arsenic by New Zealand watercress (Lepidium sativum). Sci. Total Environ. 301, 67-73.

Robinson, B., Kim, N., Marchetti, M., Moni, C., Schroeter, L., Dijssel, C., Van Den Milne, G., Clothier, B., 2006. Arsenic hyperaccumulation by aquatic macrophytes in the Taupo Volcanic Zone, New Zealand. Environ Exper Bot. 58, 206-215.

Salt, D.E., Smith, R.D., Raskin, I., 1998. Phytoremediation. Ann. Rev. Plant Physiol. Mol. Biol. 49, 643-668.

Sizova, O.I., Kochetkov, V.V., Validov, S.Z., Boronin, A.M., Kosterin, P.V., Lyubun, Y.V., 2002. Arsenic-contaminated soils: genetically modified Pseudomonas spp. and their arsenic-phytoremediation potential. Soils and Sediments. 2, 19 -23.

Smedley, P.L., Kinniburgh, D.G., 2002. A review of the source, behaviour and distribution of arsenic in natural waters. Appl. Geochem. 17, 517-568.

Smith, A.H., Lingas, E.O., Rahman, M., 2000. Contamination of drinking water by arsenic in Bangladesh: a public health emergency. Bull. World Health Organization. 78, 10931103.

Smith, S.E., Read, D.J., 1997. Mycorrhizal symbiosis. San Diego: Academic press.

Tu, C., Ma, L.Q., Bondada, B., 2002. Arsenic accumulation in the hyperaccumulator Chinese brake and its utilization potential for phytoremediation. Environ. Qual. 31, 1671-1675.

Visoottiviseth, P., Francesconi, K., Sridokchan, W., 2002. The potential of Thai indigenous plant species for the phytoremediation of arsenic contaminated land. Environ. Pollut. $118,453-461$.

Wang, J., Zhao, F.J., Meharg, A.A., Raab, A., Feldman, J., McGrath, S.P., 2002. Mechanisms of arsenic hyperaccumulation in Pteris vittata. Uptake kinetics, interactions with phosphate, and arsenic speciation. Plant Physiol. 130, 1552-1561.

Williams, P.N., Price, A.H., Rabb, A., Hossain, S.A., Feldmann, J., Meharg, A.A., 2005. Variation in arsenic speciation and concentration in paddy rice related to dietary exposure. Environ. Sci. Technol. 39, 5531-5540. 
https://webmail.adsroot.uts. edu.au/...QZBYhfl\%2b0gvxAOeUBygfAAAl \&attid0=EACDT4Y6KCnuQp8\%2fKzDImDEH\&attcnt=1[30/01/2014 11:06:40 AM] 
https://webmail.adsroot.uts. edu.au/...QZBYhfl\%2b0gvxAOeUBygfAAAl \&attid0=EACDT4Y6KCnuQp8\%2fKzDImDEH\&attcnt=1[30/01/2014 11:06:40 AM] 
https://webmail.adsroot.uts. edu.au/...QZBYhfl\%2b0gvxAOeUBygfAAAl \&attid0=EACDT4Y6KCnuQp8\%2fKzDImDEH\&attcnt=1[30/01/2014 11:06:40 AM] 
https://webmail.adsroot.uts. edu.au/...QZBYhfl\%2b0gvxAOeUBygfAAAl \&attid0=EACDT4Y6KCnuQp8\%2fKzDImDEH\&attcnt=1[30/01/2014 11:06:40 AM] 
https://webmail.adsroot.uts. edu.au/...QZBYhfl\%2b0gvxAOeUBygfAAAl \&attid0=EACDT4Y6KCnuQp8\%2fKzDImDEH\&attcnt=1[30/01/2014 11:06:40 AM] 